\title{
El mantenimiento de una estructura social de clases a través de los largometrajes de la colección «Los clásicos» Disney (1937-2016)
}

\section{The maintenance of a classes' social structure through the films of Disney collection: «the classics» (1937-2016)}

\section{A manutenção de uma estrutura social de classes através dos longas-metragens da coleção «clássicos» da Disney (1937-2016)}

\section{VICENTE MONLEÓN OLIVA | Vicente.monleon.94@gmail.com UNIVERSITAT DE VALĖNCIA | ESPAÑA}

Received - Recibido · Recebido: 12 de enero de 2020 | Accepted · Aceptado · Aceito: 14 de marzo de 2020 DOI: https://dx.doi.org/10.12795/Communiars.2020.i03.05

\section{(c) (1)(2) Artículo bajo licencia Creative Commons BY-NC-SA}

How to cite this article · Cómo citar este artículo • Como citar este artigo:

\begin{abstract}
Monleón-Oliva, V. (2020). El mantenimiento de una estructura social de clases a través de los largometrajes de la colección «Los clásicos» Disney (1937-2016). Communiars. Revista de Imagen, Artes y Educacion Crítica y Social,3, 76-94.
\end{abstract}

\section{Resumen:}

La cultura visual de la imagen y del audiovisual tiene un gran impacto en la configuración de identidades y en el desarrollo de personalidades, sobre todo, se destaca una mayor incidencia en el colectivo infantil, entendiéndose como el grupo de menores de 0-6 años quienes todavía están en un proceso evolutivo significativo para su progreso ulterior. A lo largo de la historia del arte se aprecian numerosos ejemplos que se esfuerzan por transmitir, defender y asentar una diferenciación en la estructura social de clases. Actualmente, dicha separación se materializa y perdura todavía en largometrajes de animación como los de la industria cinematográfica Disney. Debido a que hay una tendencia generalizada que recurre a estos como material de aula para que el colectivo estudiantil se 
entretenga de manera pasiva, se propone analizar los mensajes que la colección "Los clásicos" Disney (1937-2016) transmite a través de sus películas en relación a la separación de la sociedad en clases; con el fin de compartir los resultados para que las plantillas docentes se replanteen el impacto que tienen y las consecuencias sociales que son capaces de generar cuando su uso no se acompaña de una alfabetización visual de calidad. Con todo, se remarca la importancia que tiene la introducción de la cultura visual de la imagen y del audiovisual como contenido de trabajo en la Educación Infantil.

Palabras claves: Cultura visual. Imagen. Audiovisual. Disney. Estructura social de clases.

\section{Abstract:}

The visual culture of the image and the audiovisual has a great impact on the configuration of identities and the development of personalities; above all, a greater effect in the children's group stands out, being understood as the group of children under 0-6 years who are still in a significant evolutionary process for their further progress. Throughout the history of art there are numerous examples that strive to transmit, defend and establish a differentiation in the social structure of classes. Currently, this separation is still materialized and stilled in animated films such as those of the Disney film industry. Because there is a general tendency that uses these as classroom material so that the student group is entertained passively, it is proposed to analyze the messages that the collection "The Classics" Disney (1937-2016) transmits through its films in relation to the separation of society into classes; in order to share the results so that the teaching staff reconsiders the impact they have and the social consequences that they are capable of generating when their use is not accompanied by quality visual literacy. However, it highlights the importance of the introduction of the visual culture of the image and audiovisual as a work content in Early Childhood Education.

Kewords: Visual culture. Image. Audiovisual. Disney. Social class structure.

\section{Resumo:}

A cultura visual da imagem e do audiovisual tem um grande impacto na configuração das identidades e no desenvolvimento das personalidades, sobretudo, há um maior impacto na população infantil, entendida como o grupo de crianças de 0 a 6 anos que ainda se encontram num processo evolutivo significativo para o seu progresso futuro. Ao longo da história da arte há inúmeros exemplos que se esforçam por transmitir, defender e estabelecer uma diferenciação na estrutura social das classes. Hoje, essa separação se materializa e ainda perdura em filmes de animação como os da indústria cinematográfica da Disney. Como existe uma tendência geral que utiliza estes filmes como material de sala de aula para o entretenimento passivo dos alunos, propomos analisar as mensagens que a coleção "Os Clássicos" Disney (1937-2016) transmite através de seus filmes em relação à separação da sociedade nas aulas, a fim de compartilhar os resultados para que os professores possam repensar o impacto que eles têm e as conseqüências sociais que são capazes de gerar quando seu uso não é acompanhado de uma alfabetização visual de qualidade. Contudo, a importância de introduzir a cultura visual da imagem e do audiovisual como conteúdo de trabalho na Educação Infantil é enfatizada.

Palavras-chave: Cultura visual. Imagem. Audiovisual. Disney. Estrutura de classe social.

\section{Introducción}

Este artículo de reflexión encuentra su justificación en el marco de una investigación de Tesis Doctoral. Este proceso se relaciona con la revisión crítica de una colección de 60 largometrajes "Los clásicos" Disney (1937-2016) entorno al concepto metafórico de maldad como aspecto que pervierte la existencia y que dificulta el avance de la sociedad hacia una consecución de los 
derechos universales. Tras corroborar esta afirmación surgen las siguientes preguntas: ¿por qué las plantillas docentes insisten en utilizar recursos audiovisuales Disney? y ¿a qué se debe que este colectivo docente no diseñe materiales y actividades sobre Disney que contribuyan al desarrollo integral de quienes estudian de una manera activa y positiva para su formación y/o evolución?

A estos interrogantes se responde indicando que el desconocimiento y la ausencia de una formación y alfabetización visual de calidad a lo largo de su existencia es la causa que genera un desconocimiento de los mensajes perversos que transmite Disney, por ello no dudan en introducir la temática en sus aulas a partir del visionado de los filmes sin realizar los oportunos debates ni tertulias. Desde la investigación educativa y artística se pretende compartir una crítica reflexiva de este conjunto de películas respecto al tema de la estructura social de clases, para manifestar la peligrosidad que estos recursos audiovisuales tienen en relación con el mantenimiento de los sistemas democráticos.

Este es el objetivo principal de la investigación, es decir, conocer y manifestar cuál es la mentalidad Disney en relación con la estructura social de clases, saber cuáles son los mensajes que transmite a través de una de sus colecciones de animación; también determinar el impacto y consecuencias sociales que tiene la dispensación de dicha ideología en la realidad actual. Con todo, la pregunta de investigación de la que se parte es: ¿de qué manera Disney contribuye al mantenimiento de una estructura social de clases a través de largometrajes producidos a lo largo de un siglo con vigencia todavía en la cotidianidad?

\section{La cultura visual en el marco contextual y sociológico actual. Influencia de la imagen}

La humanidad recibe una gran cantidad de información visual a través de todo aquello que le rodea por medio de las distintas imágenes que envuelven su realidad. Por ejemplo, las existentes en los anuncios de televisión, los folletos de publicidad, las cartelas, las redes sociales, las ilustraciones de libros, los afiches en las paredes escolares, etc. ¿Cuál es la consecuencia directa de esta nueva distribución y acceso a la información? Como respuesta se destaca, de una manera inconsciente y paulatina, la configuración de unas formas de actuación, así como diversos patrones de conducta en quienes se nutren y reciben los mensajes (audio)visuales sin haber aprendido previamente a decodificarlos, criticarlos y cuestionarlos.

Concretamente, en la edad adulta este imaginario influye en la modificación de su identidad, aunque se presuponga ya configurada. Por ello, cuando se centra la atención en el colectivo infantil y estudiantil, quienes se encuentran en un proceso en activo de creación de identidades, todo este compendio de información les influye de una manera más directa, rápida y subconsciente (Duncum, 2007; Hernández, 2010). En cualquier caso, se precisa de una educación visual de calidad que enseñe a las personas en cualquier rango de edad a decodificar y reinterpretar los mensajes que el poder desea transmitir entre el grupo a quien desea sublevar.

Estas fuentes de información que afectan y configuran inconscientemente a las personas son, entre otras: el televisor que emite imágenes de tipo informativo, comerciales y de entretenimiento; las publicitarias que se encuentran en el entorno como las vallas gigantes, los 
mupis o las marquesinas del transporte público; sin olvidar los escaparates de las tiendas pertenecientes al visual merchandising; el cine y/o las imágenes de internet (Acaso, 2006).

Consecuentemente, si en la sociedad actual la cultura visual tiene un gran impacto, es necesario plantearse la necesidad de introducirla como recurso en cualquier aula de Educación Infantil y así conseguir unos beneficios para la construcción de la identidad del colectivo estudiantil que está empezando su escolarización. Se centra la atención en el periodo vital de 0 a 6 años ya que es en el que la recepción de información tiene mayor peso en cuanto al desarrollo de la personalidad y confección de la identidad. Esta influencia a la que se hace referencia se relaciona con el concepto de imagen compartido por Acaso (2006):

Una imagen es un sistema de representación a través del lenguaje visual, es decir, es una construcción de carácter ficticio, entendiendo por ficción aquello que no es realidad. Sin adentrarnos en una complicada disertación filosófica para diferenciar entre lo que es la realidad y lo que no lo es; las imágenes son, hoy más que nunca, tergiversaciones intencionadas de la realidad, construcciones hechas por alguien para algo, en la mayoría de los casos con intenciones muy concretas. (p.15)

Partiendo de esta referencia se establece que dichas imágenes que bombardean constantemente a los individuos de una sociedad, en lo cotidiano, no deben ser tomadas como una representación objetiva de la realidad, sino como una interpretación creada por unas personas que quieren que el resto perciban la realidad de una forma determinada, para sus propios intereses, tanto personales, como empresariales y políticos.

Muy a pesar nuestro, lo cierto es que del discurso televisivo emana un impresionante componente formativo entre el público infantil y juvenil, ese mismo público que se convierte en el alumnado de nuestras aulas. [...] el papel del educador no consiste en enfrentarse a ningún código establecido, sino ayudar a entenderlo de manera crítica y reflexiva. (Huerta, 1999, p.4)

Con todo, se debe apostar por un impulso positivo desde las aulas de Educación Infantil, las cuales deben de favorecer la alfabetización visual, la educación en y para los medios de comunicación en una época ya tildada de postdigital (Jandric, Knox, Besley, Ryberg, Suoranta y Hayes, 2019). Así como también del conjunto de sonidos musicales que acompañan y envuelven a estas producciones ya que influyen y tienen su importancia como influjo de información (Alonso-Sanz y Romero-Naranjo, 2014).

\section{La Disney separatista y clasista. Un ejemplo de perduración de una ideología defensora de la separación social entre clases a partir de los largometrajes de la colección cinematográfica de animación "Los clásicos" (1937-2016)}

La productora Disney es una industria del cine que apuesta por unas estructuras sociales rígidas que dividen la población entre el grupo de poder y el colectivo opuesto que se subleva al primero; entablándose una lucha entre ambos bandos (Reguillo, 2005; Ros, 2007). "La cultura Disney define a los ciudadanos principalmente como consumidores y espectadores que 
asumen valores conservadores e inmovilistas y no cuestionan el orden social" (Digón, 2006, p.166). De hecho, Marí-Sáez (1998) menciona en su trabajo esta visión jerarquizada que ofrece la compañía citada en sus creaciones, mostrándola como un suceso natural, cíclico e inamovible. Esperando construir una sociedad conformista y desesperanzada en la promoción de intentos para cambiar su situación vital en la comunidad (Digón, 2006). "Temas como el capitalismo y el imperialismo en las animaciones de Disney: su justificación de la avaricia, su mala lectura de la explotación, su punción ante los atrasados salvajes" (Guitlin, 2001, p.14). Con todo, resulta significativo compartir los estereotipos que Ros (2007) establece en cuanto a las clases sociales bajas, quienes son etiquetadas como perversas, amorales y carentes de ética. "Estereotipos que están presentes en nuestra sociedad: inmigrante económico = delincuente; $[\cdots]$ árabe = terrorista, fanático religioso; judío = tacaño; gitano = ladrón" (p.10).

Concretamente, ¿en cuántos y en qué largometrajes se presenta la variable de la estructura social de clases? A lo largo de los 60 largometrajes de la colección "Los clásicos" Disney (19372016) esta constante se aprecia en un total de 30 filmes. Estos son: Blancanieves y los siete enanitos (Disney, 1937), Fantasía (Disney, 1940), Bambi (Disney, 1942), La leyenda de Sleepy Hollow y el señor sapo (Disney, 1949), Alicia en el país de las maravillas (Disney, 1951), La dama y el vagabundo (Disney, 1955), Merlín, el encantador (Disney, 1963), Mary Poppins (Disney y Walsh, 1964), El libro de la selva (Disney, 1967), Los Aristogatos (Hibler y Reitherman, 1970), Robin Hood (Reitherman, 1973), Lo mejor de Winnie the Pooh (Disney, 1977), Los rescatadores (Miller y Reitherman, 1978), Tod y Toby (Miller, Reitherman y Stevens, 1981), Taron y el caldero mágico (Hale, 1985), Básil, el ratón superdetective (Clements, Mattinson y Musker, 1986), Oliver y su pandilla (Gavin, 1988), La sirenita (Ashman y Musker, 1989), El rey león (Hahn, 1994), Mulan (Coats, 1998), Fantasía 2000 (Disney y Ernst, 2000), El emperador y sus locuras (Fullmer, 2000), Salvaje (Flynn y Goldman, 2006), Tiana y el sapo (del Vecho y Lasseter, 2009), Enredados (Conli, 2010), ¡Rompe Ralph! (Spencer, 2012), Frozen: el reino de hielo (del Vecho y Lasseter, 2013), 6 héroes (Conli, Lasseter y Reed, 2014), Zootrópolis (Spencer, 2015) y Vaiana (Shurer, 2016). A continuación, se reflexiona críticamente sobre la variable de la estructura social de clases y su materialización y representación en los 30 filmes indicados; promoviendo así una estética descolonial (Pérez, 2019). Concretamente, se atiende a los siguientes ítems: la diferenciación de dos espectros sociales opuestos, el uso de la imagen como promotora de diferencia social, la monarquía como forma política, la visión imperialista, el impulso positivo hacia quienes tienen el poder y la percepción idílica de la clase social elevada.

\subsection{La diferenciación de dos espectros sociales opuestos}

Se manifiesta como notorio en esta colección de largometrajes el ítem de la diferenciación de dos espectros sociales opuestos, ya que se etiqueta en un total de 15 largometrajes. Se destaca que es una constante a lo largo del siglo de existencia en el que se distribuye temporalmente esta colección, desde su primer filme hasta el último. Disney se esfuerza por diseñar en sus historias dos bandos sociales totalmente diferenciados y opuestos, estableciendo así un binomio social de poder-sublevación, dominio-esclavitud, incluso riqueza-pobreza. Se esfuerza por mantener esta concepción social que perdura en la realidad, potenciando la existencia de grupos sociales que siguen a sus superiores, líderes, monarcas, etc., sin cuestionarse ni enseñarles a criticar los mandatos y órdenes que reciben. 
Por un lado, se atiende a la oposición generada entre quienes son monarcas y quienes son súbditos. Por ejemplo, en Blancanieves y los siete enanitos (Disney, 1937) mientras que la soberana Grimhilde se presenta como la suprema monarca del reino, sus seguidores se tildan de "esclavos". En Bambi (Disney, 1942) todo el reino del bosque se dirige hacia este como "príncipe", le guarda respeto, le protege e incluso asisten a su nacimiento; de manera similar al respeto y distanciamiento que presentan con respecto al rey, únicamente Bambi debido a su condición real entabla conversación con su superior. En películas como El libro de la selva (Disney, 1967) o El rey león (Hahn, 1994) esta visión separatista de la sociedad se materializa con animales, siendo en la primera el tigre un soberano y tirano líder de la selva de la India, mientras que en la segunda es el león el animal presentado como admirable rey de la sabana africana. Esto mismo ocurre en Robin Hood (Disney, 1977) ya que se recurre al linaje de leones como figura para representar la realeza de Inglaterra en la Edad Media. Asimismo con el alcalde de la ciudad en Zootrópolis (Spencer, 2015) que es un león. También con Samson en Salvaje (Flynn y Goldman, 2006) presentado con las siguientes intervenciones: "lanzarles mi gran rugido", "y ahí estoy yo, frente al leopardo más grande y cruel", "¿te he contado cuando les borré de la cara las risitas a las hienas?", "y, ¿lo del cocodrilo?" y "capitán del equipo y ahora del barco". De hecho, resulta significativo y peligroso en términos de progreso social la manera en la que se achaca a algunas figuras cuando carecen de poder ni estatus social versus a la manera en la que se les acoge cuando asciende en la escala social, este es el caso de Vanellope, la joven protagonista de un juego de carreras, quien es sentenciada al rechazo cuando es tildada de glitch, pero exaltada por la ciudadanía cuando se descubre su verdadera condición de princesa en ¡Rompe Ralph! (Spencer, 2012). Un último ejemplo de respeto a la soberanía real es el hallado en la reina Elsa de Frozen: el reino de hielo (del Vecho y Lasseter, 2013).

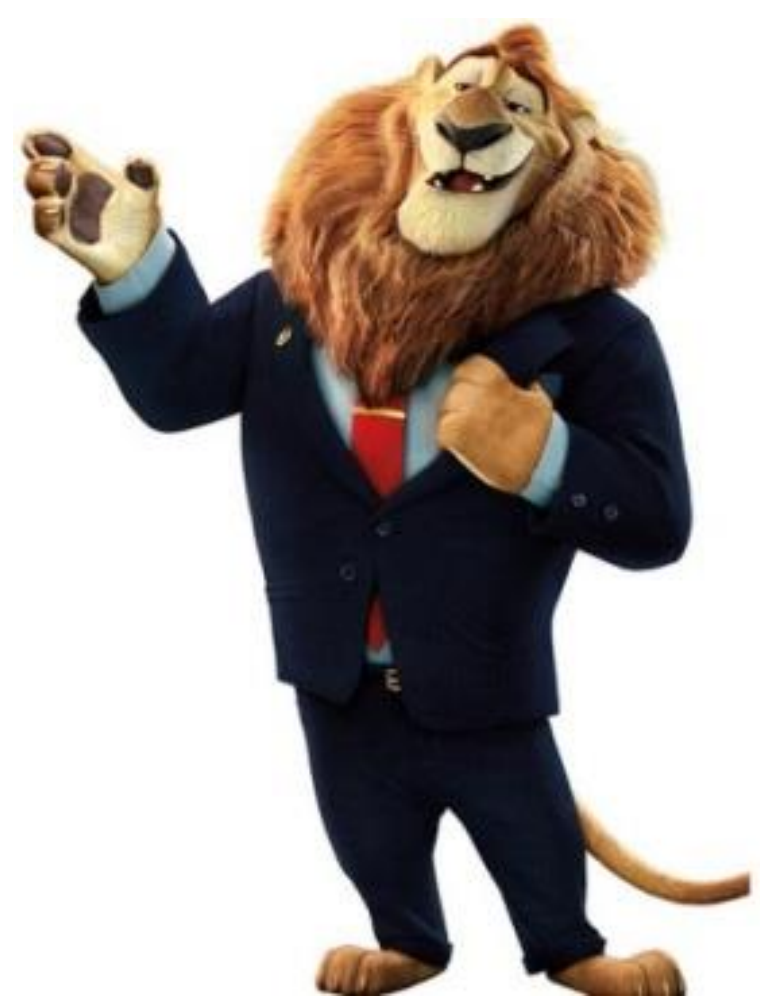

Figura 1. Walt Disney (2015). Alcalde de Zootopía [Figura]. En Zootrópolis (Specer, 2015) 
Por otro lado, aparece el concepto de "líder" en estas películas, considerada como una persona a la que el resto de iguales o inferiores le siguen, guardándole respeto y sumisión. Disney justifica esta concepción atribuyendo una capacidad de liderazgo innata en quienes dirigen y una carencia de aptitudes para el cuestionamiento y la crítica hacia quienes ocupan escalones más altos de la estructura social. Por ello, siguen sus mandatos e indicaciones sin una reflexión previa. El primer largometraje en el que se dispensa dicha concepción es en Fantasía (Disney, 1940), concretamente en el cortometraje "La danza de las horas" ya que presenta diversos grupos de animales en los que siempre hay un miembro que dirige al resto y se le distingue por un complemento característico y único. Le sigue el filme Los Aristogatos (Hibler y Reitherman, 1970) con la pareja de sabuesos que viven en el campo. En dicho grupo hay uno que tiene preponderancia (Napoleón) mientras que el restante (Lafayette) sigue sus indicaciones simplemente. De hecho, se materializa con algunas intervenciones: "porque soy tu superior, solo por eso" y "un momento, yo soy el jefe y soy quien debe dar la orden". Esto mismo ocurre con Conejo cuando a Winnie y Piglet en Winnie the Pooh (Disney, 1977) tras recurrir a su capacidad oratoria para convencer a la pareja de animales de abandonar a Tigger en el bosque y obligarle a que cese su actividad de brinco.

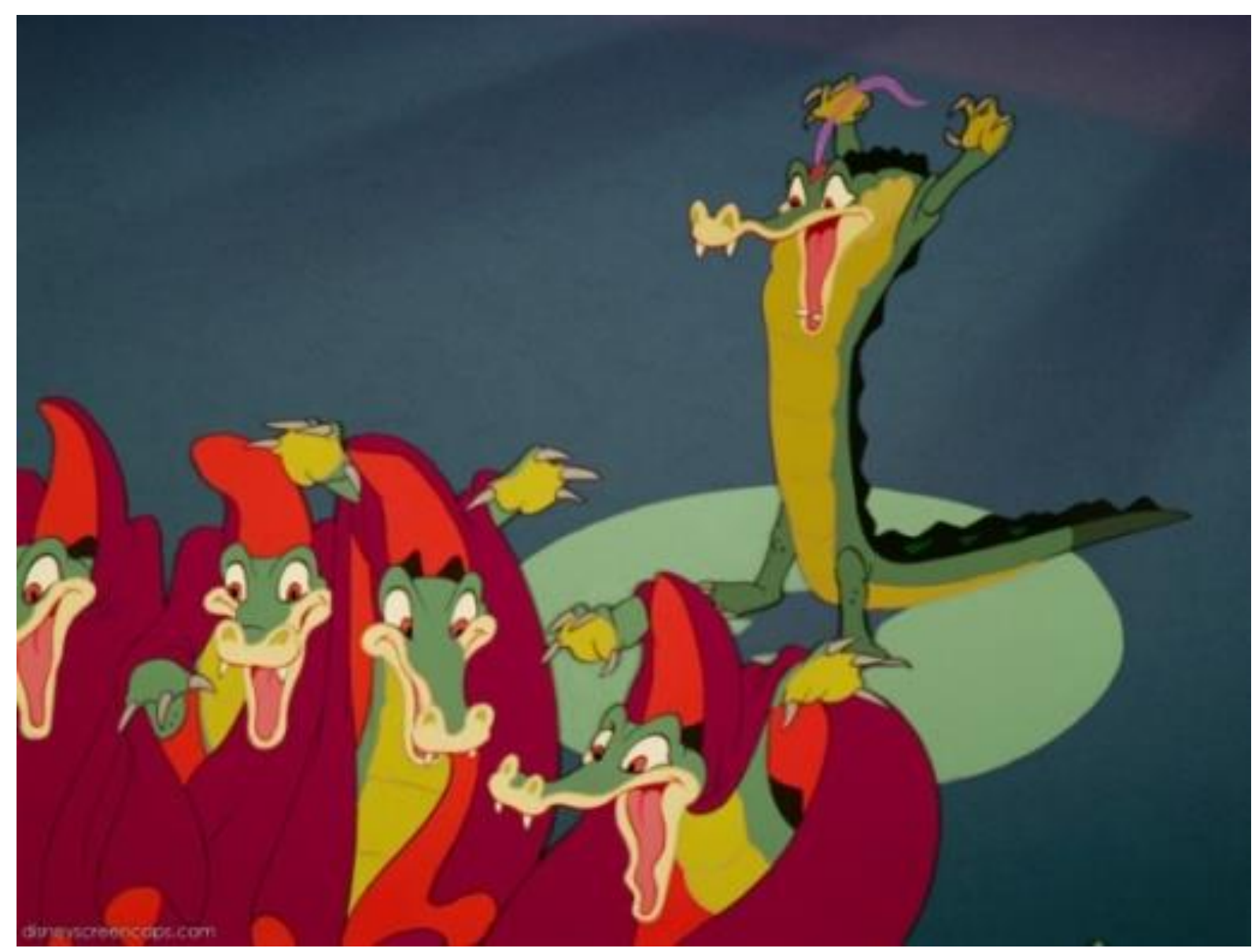

Figura 2. Walt Disney (1940). Líder de los aligátores con tocado en la cabeza y grupo de seguidores [Figura]. En Fantasía (Disney, 1940)

Asimismo, en relación con este ítem se manifiesta también una diferencia entre bandos sociales justificada en términos económicos y de renta. Disney es una fiel defensora de los derechos capitalistas de las personas adineradas, ya que son estas quienes posibilitan las producciones 
de muchos de sus largometrajes, además es el colectivo social en el que el propio director y creador Walter Disney se ubica. De hecho, esta separación económico-social es una constante y se repite en numerosos ejemplos de la colección. En el caso de La leyenda de Sleepy Hollow (Disney, 1949) con el cortometraje de "El seño sapo" se materializa con una distinción en el vocabulario y con expresiones utilizadas para dirigirse a cada colectivo. Por ello, se recurre a cultismos de la lengua cuando la conversación se dirige hacia Sr. Toad, pero se opta por expresiones más despectivas con respecto a otros colectivos menos adinerados "ese gitano Cirilo". Este patrón lingüístico se repite en Básil, el ratón superdetective (Clements, Mattinson y Musker, 1986). Básil y Dawson pertenecen a la clase social elevada de la Inglaterra de principios de siglo $\mathrm{XX}$, por ello utilizan un registro normativo en sus conversaciones, a excepción de cuando se introducen en los suburbios de la ciudad buscando al grupo de delincuentes: "recuerde Dawson que somos del bajo mundo". Al igual que en este filme, en 6 héroes (Conli, Lasseter y Reed, 2014) se materializa esta diferenciación con la descripción de dos barrios económicamente diferenciados. Cuando se posiciona la mirada en los largometrajes de animales, esta diferenciación económica se plasma en quienes son de raza pura y viven en hogares acomodados, mientras que quienes son mestizos y viven en las calles o perreras se les considera y destinan escalones sociales bajos. Los ejemplos más destacados son La dama y el vagabundo (Disney, 1955) y Oliver y su pandilla (Gavin, 1988).

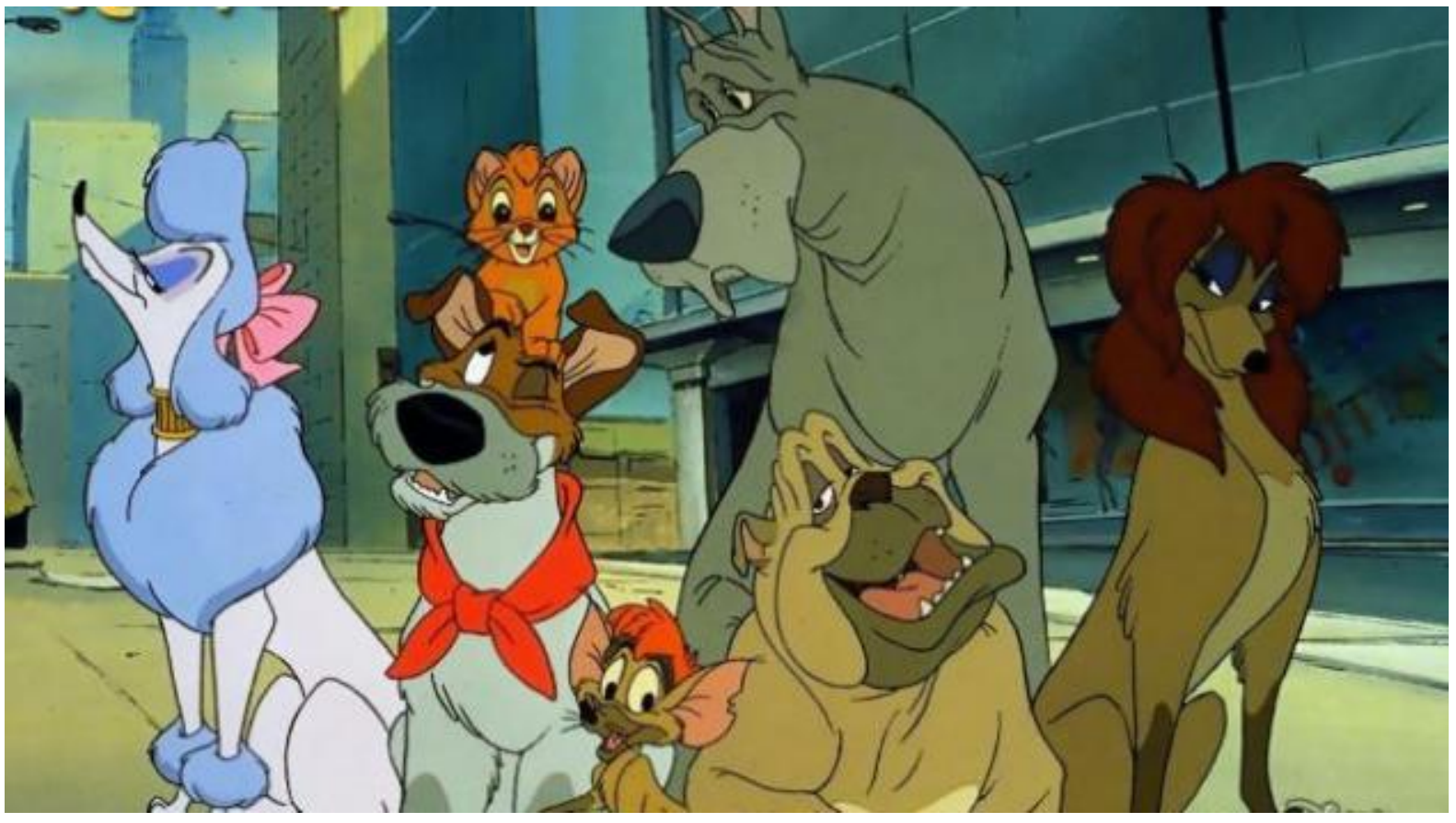

Figura 3. Walt Disney (1988). Georgette versus animales callejeros [Figura]. En Oliver y su pandilla (Gavin, 1988)

También se distinguen los bandos sociales dependiendo de la profesión que desarrollen las figuras. Con esta faceta, Disney muestra su componente separatista y juicioso, de una manera sesgada, tras considerar y atribuir mayor importancia y reconocimiento social de unas profesiones frente a otras, dignificando a unas e infravalorando a otras. Por ejemplo, en Merlín, el encantador (Disney, 1963) Grillo es un sirviente y ayudante de escudero mientras que su hermanastro legítimo es un caballero: "Soy un pobre huérfano y un caballero debe ser de clase noble". Otras profesiones como la policía queda exaltada, por ello cuando Bert de Mary Poppins (Disney y Walsh, 1964) pide un cobro a la audiencia tras la interpretación de canciones, 
prescinde de la caridad del guardia, teme que le arreste por su condición callejera, de hecho lo indica con la siguiente intervención: "¡Ah no, usted no, usted gratis!". En Los rescatadores (Miller y Reitherman, 1978) genera un gran revuelo en la Sociedad de Salvamente Eficaz la decisión de Miss Bianca, representante de Hungría, respecto a que Bernardo, el conserje de dicho lugar, sea su acompañante en la misión de rescate de Penny; tal y como entiende Disney la sociedad, no es posible la mezcla de personas pertenecientes a escalas sociales diferentes: "una dama y un conserje, ¡cielos, qué combinación!". Esta visión social Disney también aparece reflejada en Taron y el caldero mágico (Hale, 1985) con el asombro de Elena hacia Taron cuando descubre que este es un porquero y no un caballero, ya que de acuerdo con las enseñanzas recibidas de corte estamental, un hombre de su condición no tiene dotes para salvar a una princesa. Asimismo, se rescata la profesión de Shang en Mulan (Coats, 1998) como general de las tropas de China, gracias a la cual adquiere su reconocimiento y prestigio social.

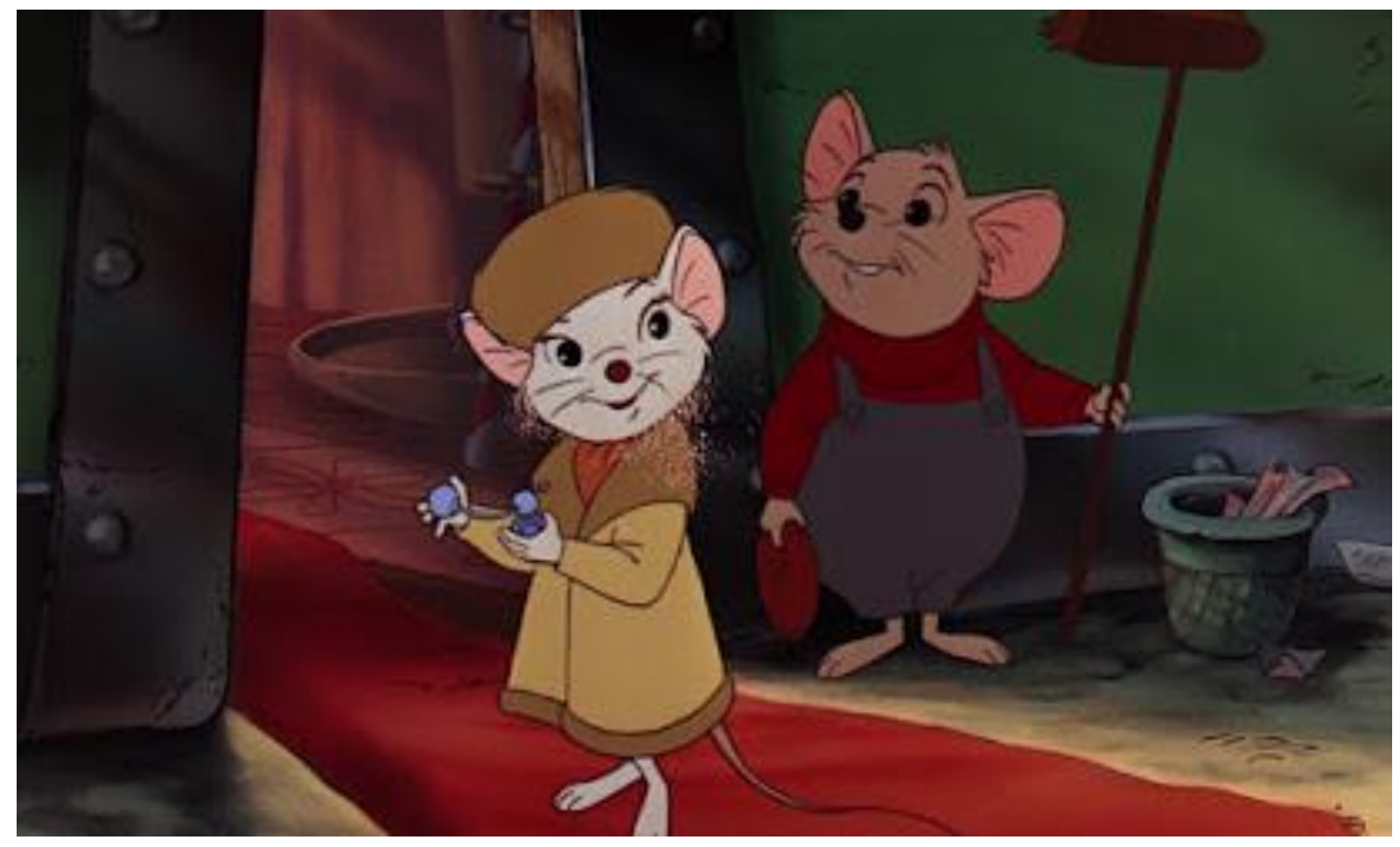

Figura 4. Walt Disney (1978). Bianca como dama versus Bernardo como conserje [Figura]. En Los rescatadores (Miller y Reitherman, 1978)

Otras manifestaciones de la diferenciación de dos espectros sociales son las presentadas a continuación. Por una parte, el condicionante de la edad. Disney entiende, de una manera un tanto cuestionable, que aquellas personas pertenecientes a la madurez son aquellas con una experiencia mayor y que por tanto son privilegiadas con determinados beneficios. Por ello, en Tod y Toby (Miller, Reitherman y Stevens, 1981), cuando Toby es un cachorro queda relegado a viajar en la parte trasera del vehículo de su dueño, mientras que el jefe es quien le acompaña en los asientos delanteros como su copiloto y así se lo comunica su superior: "tú vas atrás novato, tienes que ganar el derecho de viajar aquí". Por otra parte, la raza como diferenciadora de clases sociales. La Disney racista eleva el poder de quienes pertenecen al linaje blanco mientras que achaca a quienes se relacionan con el negro. Tiana como mujer negra en Tiana y el sapo (del Vecho y Lasseter, 2009) tiene serias dificultades para convertirse en mujer de negocios con la apertura de su restaurante de lujo, mientras que su amiga y noble Charlotte dispone de riquezas para cumplir sus sueños. 


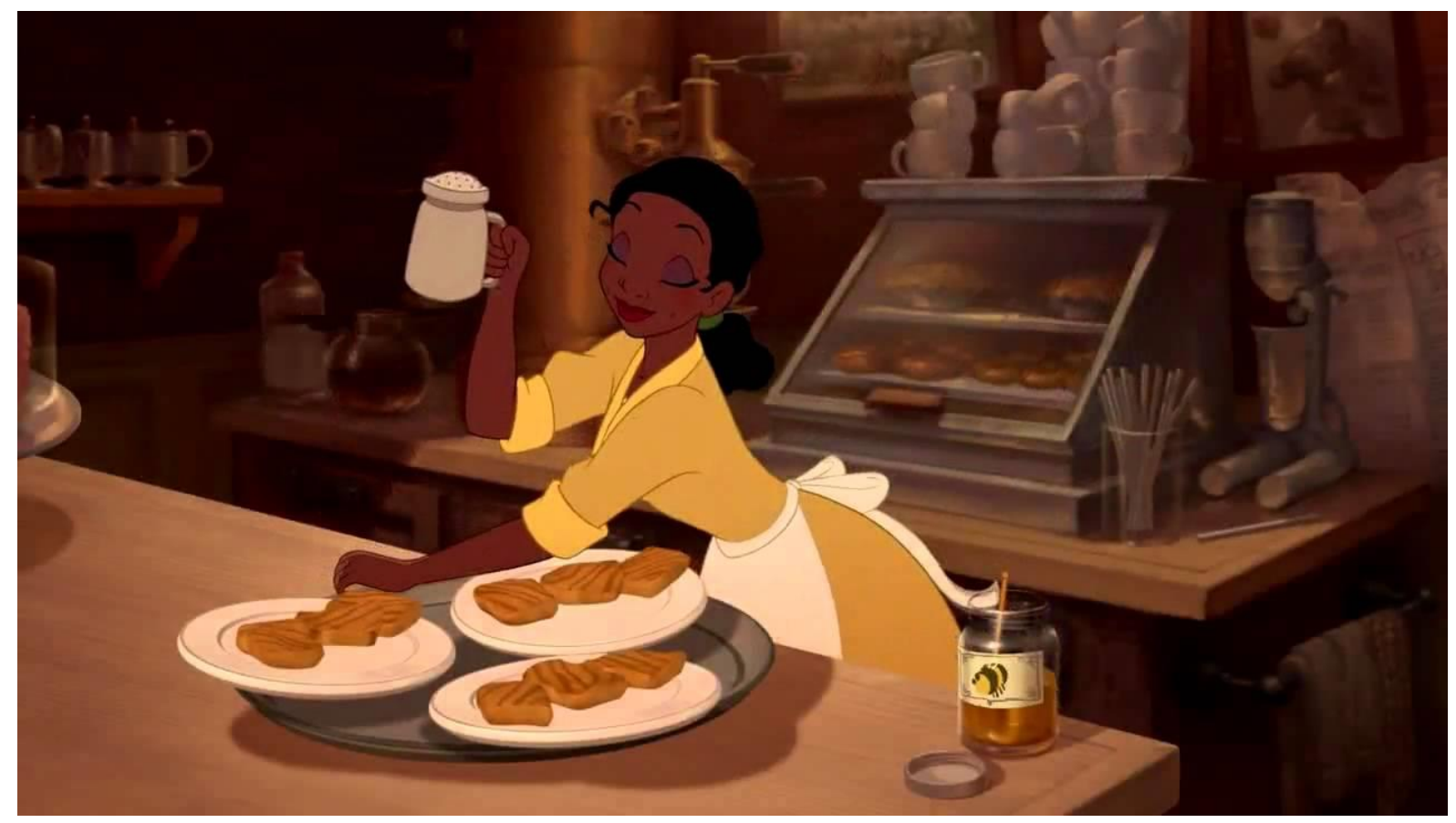

Figura 5. Walt Disney (2009). Tiana como ejemplo de la raza negra perteneciente a la clase trabajadora [Figura]. En Tiana y el sapo (del Vecho y Lasseter, 2009)

Finalmente, Disney perdura en sus creaciones audiovisuales una concepción hereditaria del poder, según la cual no se necesitan más aptitudes para liderar a un conjunto de personas que disponer y pertenecer a una familia con poderío. Por ello, en Vaiana (Shurer, 2016) ella es la única mujer capaz de devolver la tranquilidad a las islas de los mares del sur de Indonesia, ella es la hija del jefe de la tribu. Con mensajes como este, se potencia una visión conformista en la sociedad que niega la posibilidad a que valores como el trabajo, el esfuerzo y el tesón sean implementados por la ciudadanía para mejorar su calidad y condición de vida; según el mensaje sesgado y erróneo Disney únicamente es posible disponer de privilegios si se nace en una familia que ya dispone de estos.

Figura 6. Walt Disney (2016). La coronación de Vaiana [Figura]. En Vaiana (Shurer, 2016)

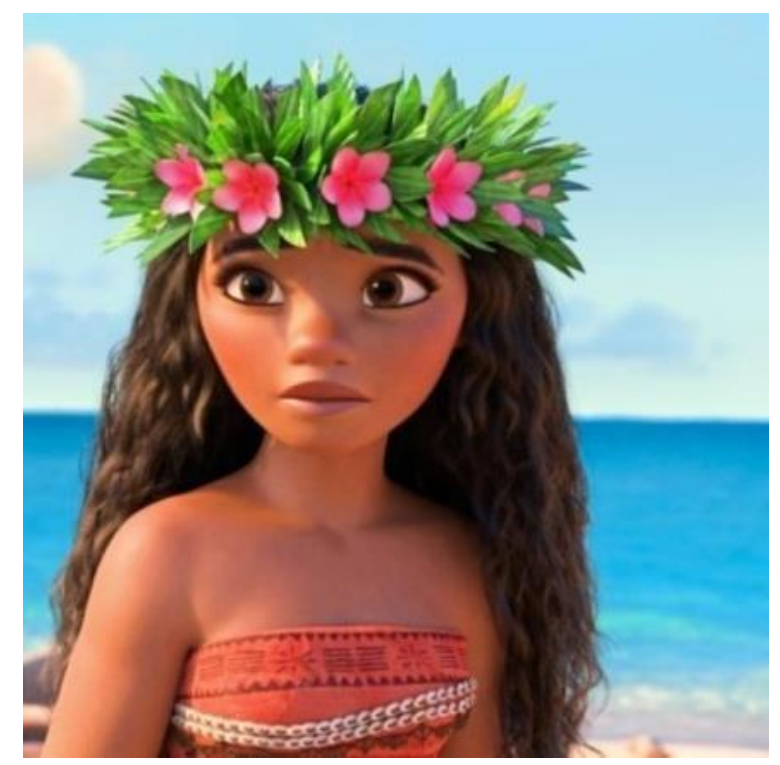




\subsection{El uso de la imagen como promotora de diferencia social}

La imagen es un refuerzo utilizado desde sus orígenes para la transmisión de mensajes, ideologías y mentalidades. De hecho, en el audiovisual es el recurso básico que acompaña al discurso, complementándolo e incluso en ocasiones relegándolo a un segundo plano. Concretando en la estructura social de clases como variable analizada, criticada y discutida en esta colección de filmes Disney, se advierte que hay un total de 5 en los que la idea de binomio escalón social alto-bajo se materializa con fotogramas que transmiten esta concepción de una manera visual y directa.

Por un lado, en Blancanieves y los siete enanitos (Disney, 1937) la reina Grimhilde ocupa las alcobas de las torres más elevadas de su castillo. No obstante, cuando se transforma en mujer de edad avanzada para engañar a su hijastra desciende a las mazmorras de dicha fortificación, transmitiendo así una idea visual de descenso en la escala social de clases. Este concepto de altura e idea de declive se aprecia en el largometraje Alicia en el país de las maravillas (Disney, 1950) cuando tanto ella como el resto de animales corre alrededor de una roca situada a orillas del mar - situación que conlleva que continuamente se mojen - a excepción de Dodo el ave que les lidera y que se ubica en la cima de peñasco calentándose con una fogata, quien evidentemente sí que se seca y calienta. De esta manera, se ejemplifica de una forma visual como la clase social alta ubicada en la cima, mientras que la baja al ras del suelo.

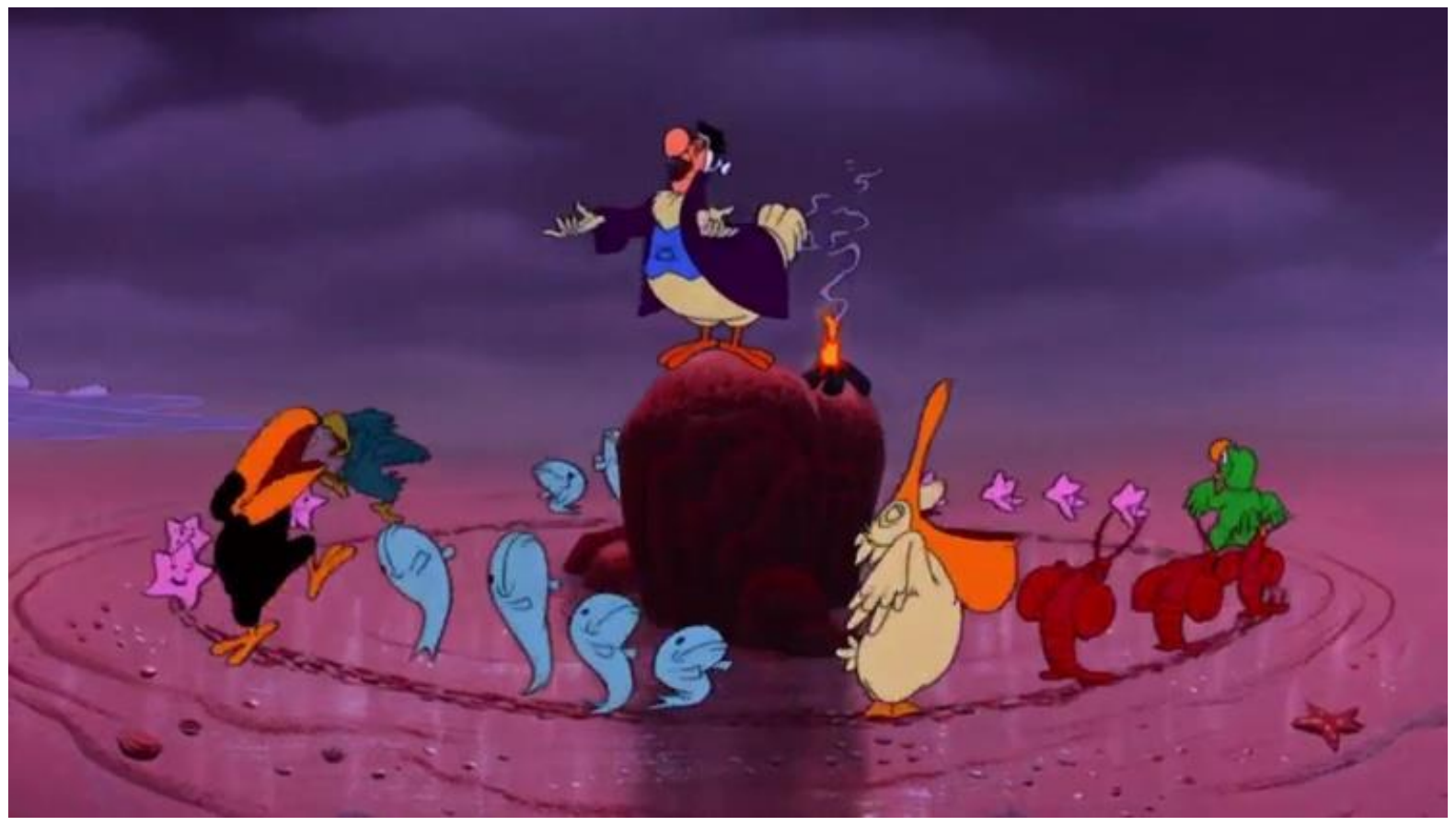

Figura 7. Walt Disney (1951). Ejemplo visual de la escala social de clases. En Alicia en el país de las maravillas (Disney, 1951)

Por otro lado, la grandeza de unos grupos frente a otros se representa con el tamaño que Disney diseña en sus figuras. En el caso de Bambi (Disney, 1942), el rey del bosque es el único animal de tamaño superior al resto, para transmitir así una idea de grandeza en su ser. 


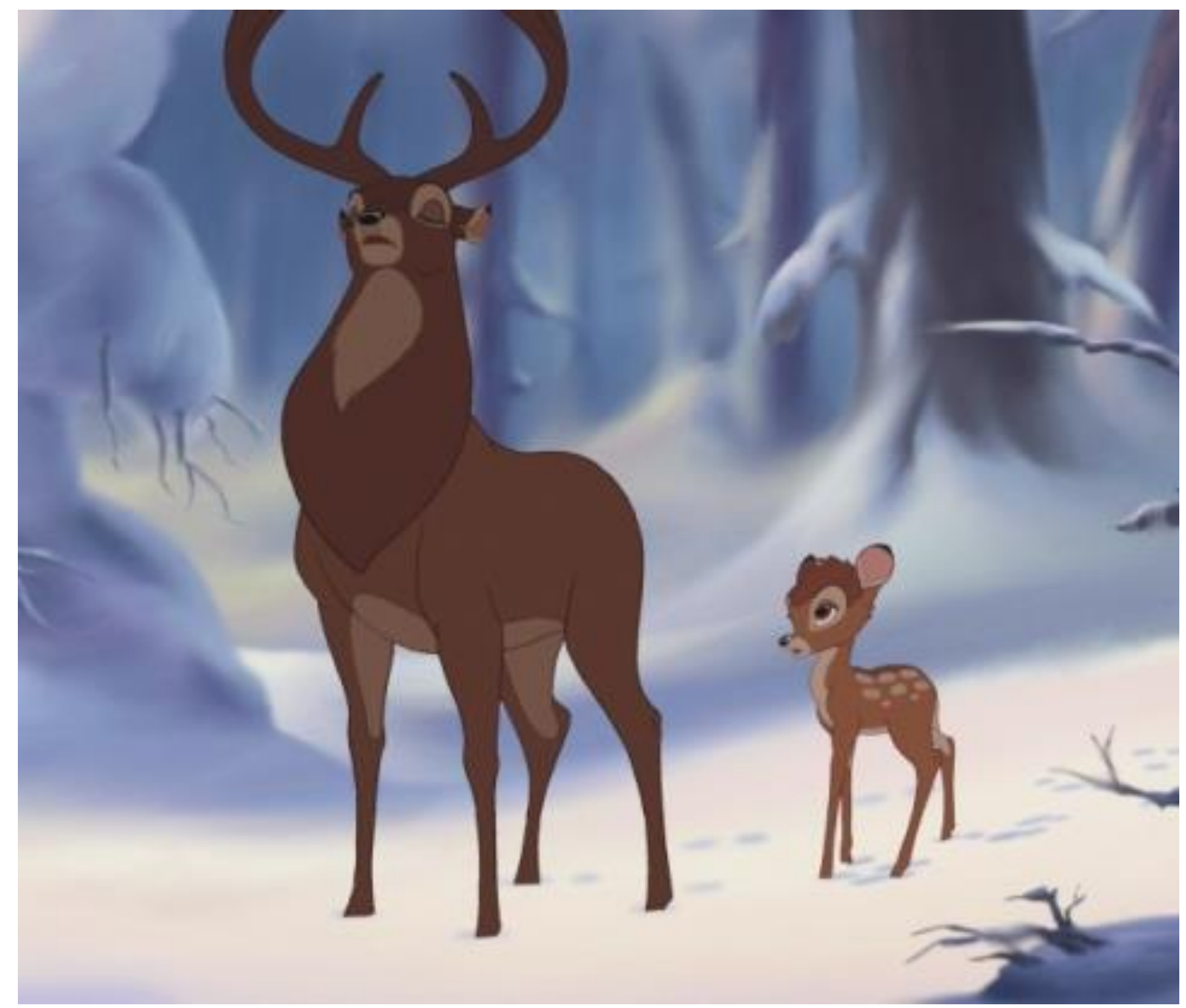

Figura 8. Walt Disney (1942). La grandeza relacionada con el poder [Figura]. En Bambi (Disney, 1942)

Con todo, en Tiana y el sapo (del Vecho y Lasseter, 2009) y 6 héroes (Conli, Lasseter y Reed, 2014) hay un recorrido visual de la ciudad en la que se divide esta en barrios. Los más altos o ubicados en la cima de las colinas corresponden con los de las clases sociales altas y con privilegios, mientras que los bajos con los de aquellas personas sublevadas y que limitan su existencia a acatar las órdenes que sus superiores les imponen.

\subsection{La monarquía como forma política}

A la Disney separatista, capitalista, racista y doctrinal se le añade como característica el impulso que ofrece a la defensa de la monarquía como forma política idílica de control social. La mentalidad de la productora trabaja en sus largometrajes por ofrecer un impulso positivo a esta forma de gobierno. Se conoce que hay una gran cantidad de largometrajes en esta colección en la que las figuras protagonistas pertenecen a la realeza. No obstante, no simplemente se recurre a estas para analizar el conjunto desde la variable de la estructura social de clases, como ya realizan otras investigaciones (Gómez, 2017; Casado, 2018), sino que se detiene la atención en aquellos ejemplos que suponen una verdadera diferenciación e impedimento para el progreso social. Concretamente se etiqueta esta característica monárquica en 7 largometrajes. 
El primer ejemplo de esta superioridad real reside en Alicia en el país de las maravillas (Disney, 1951) contemplándose una visión autoritaria en esta forma de gobierno. De hecho, se realiza un juicio contra Alicia para valorar si es la responsable de actos contra la corona o por el contrario probar su inocencia. No obstante, dicho juicio se aleja de la idea reflejada de este en una sociedad democrática y es sentenciada por la propia reina. Tal y como comenta el gato risón: "solo se puede saber lo que dispone la reina". A este le sigue el filme Robin Hood (Disney, 1973) en el que también aparece la figura totalitaria del rey y defendida como válida; así como Básil, el ratón superdetective (Clements, Mattinson y Musker, 1986) con el ejemplo real de la reina de Inglaterra, El rey león (Hahn, 1994) con una estructural animal en la sabana para ejemplificar la organización monárquica, Enredados (Conli, 2010) con la siguiente intervención: "pasaron los siglos y en menos que canta un gallo nació un reino; el reino lo gobernaban unos reyes queridos por todos"; o ¡Rompe Ralph! (Spencer, 2012). Destaca el caso de La sirenita (Ashman y Musker, 1989) ya que hay intervenciones que exaltan el poder y la superioridad del rey Tritón con respecto al resto de habitantes del océano: "el soberano del reino de las sirenas" y/o "su real majestad el rey Tritón".

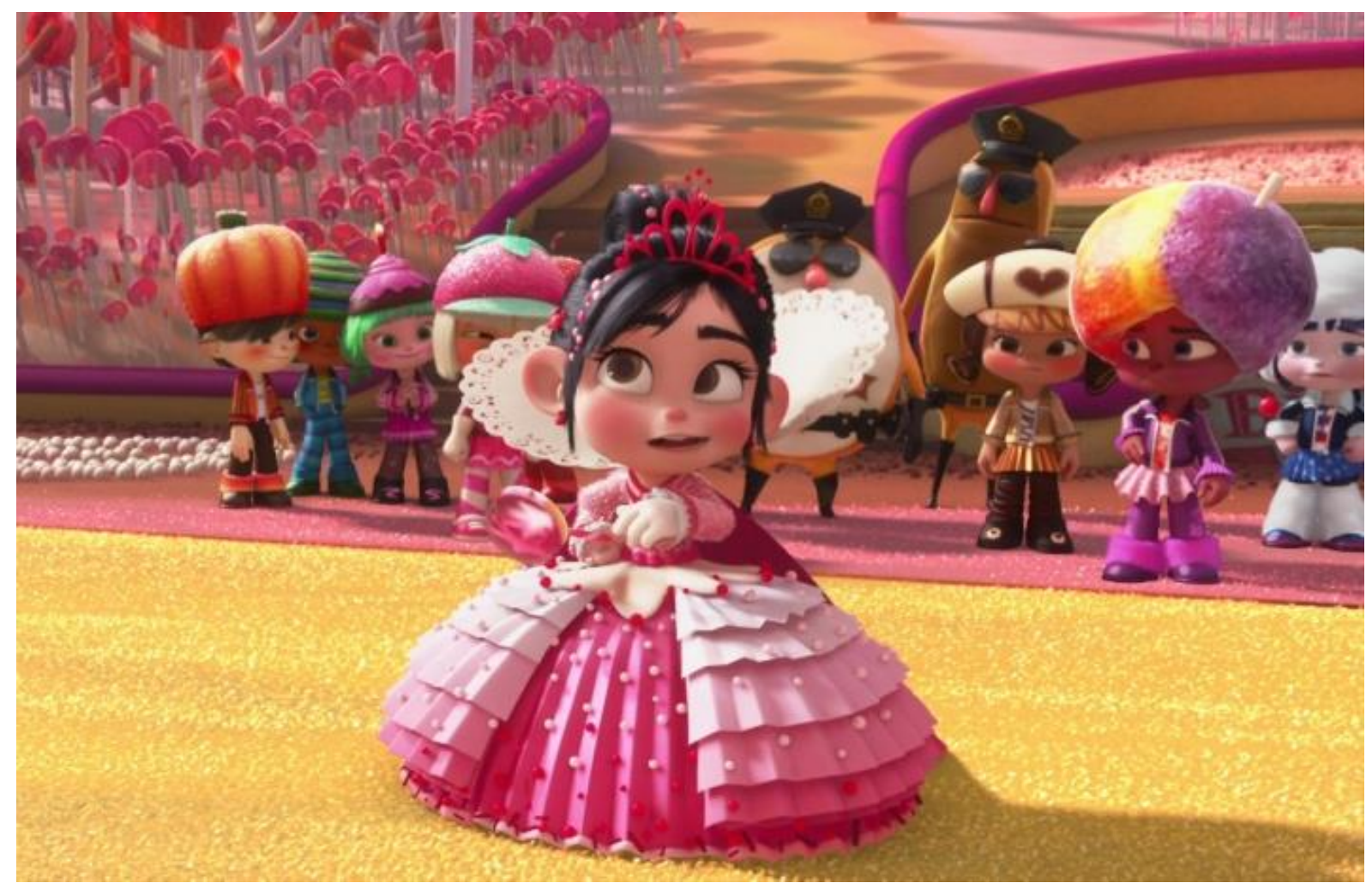

Figura 9. Walt Disney (2012). La princesa Vanellope y la ciudadanía de su juego [Figura]. En ;Rompe Ralph! (Spencer, 2012)

\subsection{La visión imperialista}

Paralelamente a la tendencia monárquica de esta industria de cine de animación también se manifiesta una apuesta por el imperialismo como modelo de gobierno ideal para la sociedad. Esta tendencia se recoge en dos filmes. Concretamente, Mulan (Coats, 1998) y El emperador y sus locuras (Fullmer, 2000). De hecho, en ambas películas se habla de imperios y los castillos medievales se sustituyen por palacios de culturas antiguas como la china y la inca 


\subsection{La percepción idílica de la clase social elevada}

La característica de la percepción idílica de la clase social elevada aparece en el largometraje La dama y el vagabundo (Disney, 1955). Todo el filme es un compendio de características propias del mundo occidental, entendiendo esa esfera social de gente adinerada y burguesa apartada del resto de mundo ajetreado y precario. No se muestra la alteridad, ya que tampoco conviene darla a conocer entre el grupo de personas acomodadas. En el filme se dice: "en el mundo hay armonía y alegría", aunque falta matizar que solo se ofrece en los millonarios barrios norteamericanos; no es una situación extrapolable al resto del mundo.

\section{Consideraciones finales}

Como reflexión final, tras la crítica de la estructura social de clases defendida por la productora Disney en su colección "Los clásicos" (1937-2016) se aprecian las siguientes constantes:

- Hay una tendencia histórica en la industria en diferenciar dos bandos sociales totalmente opuestos entre los que según su visión no es posible o no debe serlo la combinación entre sus miembros ni el paso de un escalón a otro. Por ello, se manifiesta una predisposición de corte estamental. Tras esta situación se presentan diversas explicaciones, entre otras: la defensa del capitalismo como política económica, la ideología monárquica y/o la edad como condición sine qua non del respeto y poder que posee una persona. No obstante, esta visión defendida, recreada y transmitida por Disney dificulta un progreso social hacia el desarrollo de comunidades en las que la ciudadanía tiene más oportunidades y desarrolla un empoderamiento mayor.

- Se manifiesta una relación entre el concepto de "poder" con su ubicación en los lugares más elevados, coincidiendo también con la estructura de la pirámide social. Todo ello queda reflejado a través de imágenes en los filmes en los que aparecen elevados castillos, monarcas situados en tronos altos, etc.

- Consecuentemente, partiendo de estas dos conclusiones, Disney defiende una monarquía como política idílica para asegurar el control social. Según esta productora esta es una opción válida que asegura el progreso. No obstante, se reflexiona sobre la ausencia de otras formas de poder como legítimas también para los territorios, transmitiendo así un único modelo político en quienes consumen los largometrajes y, manifestando nuevamente, una forma de adoctrinamiento político-social.

- En paralelo a este ímpetu que defiende la recopilación de todos los poderes del estado en una persona, simplemente por herencia familiar y sin una preparación previa al respecto; se añade la visión de la Disney imperialista. Según esta se presenta como válida una forma de poder que atenta contra la integridad de la alteridad, de la cultura diversa y de la multiplicidad de razas y etnias. De hecho, de manera opuesta se tolera una forma de gobierno que utiliza la fuerza, represión y guerra como una manera de expansión. Este mensaje también necesita una reflexión y crítica, sobre todo partiendo de la manera en la que influye en el colectivo infantil consumidor de estos productos. 
- Finalmente, con independencia de exaltar unas formas de gobierno versus otras, incluso de manifestar la necesidad de separación social en bandos por una cuestión económica y de estatus; se critica que se deposite únicamente la virtud en quienes son portadores del poder, al tiempo que se achaca a quienes deben sublevarse a las imposiciones que se emiten desde arriba. Esta es una forma más de control y represión social que debe ser eliminada de las estructuras sociales y comunitarias.

Con todo, una vez compartidas las pretensiones Disney a través de sus producciones de animación en una colección producida a lo largo de un siglo, es necesario plantear la importancia de compartir estos resultados entre quienes consumen estos audiovisuales de manera pasiva y sin reflexión al respecto. Se les está incidiendo en el desarrollo de una mentalidad e ideología política sin cuestionamiento y de manera subversiva. Especialmente, se apuesta por una educación del audiovisual y de la imagen de calidad en la educación española que se inicie en la Educación Infantil y que sirva como motor de cambio social, favoreciendo así la alfabetización visual. Esta es la única posibilidad de liberación de los lastres que generan y que conllevan los medios de comunicación de masas tanto históricos como modernos.

\section{REFERENCIAS DOCUMENTALES}

Acaso, M. (2006). Esto no son las Torres Gemelas. Cómo aprender a leer la televisión y otras imágenes. Madrid: Los Libros de la Catarata.

Alonso-Sanz, A. y Romero-Naranjo, F. J. (2014). Uso de los anuncios televisivos como recurso didáctico en las disciplinas artísticas. Las 'panaderas' XII Jornadas de Redes de Investigación en Docencia Universitaria 2014. El reconocimiento docente: innovar e investigar con criterios de calidad. Universidad de Alicante. Instituto de Ciencias de la Educación de la Universidad de Alicante.

Ashman, H. y Musker, J. (productores) y Clements, R. y Musker, J. (directores). (1989). La sirenita [Cinta cinematográfica]. Estados Unidos: Walt Disney Pictures.

Casado, L. (2018). El fantástico mundo heteropatriarcal de Disney. Actas de Periodismo y Comunicación, 4(2), 1-16.

Clements, R., Mattinson, B. y Musker, J. (productores) y Clements, R., Mattinson, B., Michener, D. y Musker, J. (directores). (1986). Básil, el ratón superdetective [Cinta cinematográfica]. Estados Unidos: Walt Disney Animation Studios y Walt Disney Pictures.

Coats, P. (productor) y Cook, B. y Bancroft, T. (directores). (1998). Mulan [Cinta cinematográfica]. Estados Unidos: Walt Disney Pictures y Walt Disney Feature Animation.

Conli, R., Lasseter, J. y Reed, K. (productores) y Hall, D. y Williams, C. (directores). (2014). 6 héroes [Cinta cinematográfica]. Estados Unidos: Walt Disney Animation Studios.

Conli, R. (productor) y Greno, N. y Howard, B. (directores). (2010). Enredados [Cinta cinematográfica]. Estados Unidos: Walt Disney Animation Studios. 
Del Vecho, P. y Lasseter, J. (productores) y Buck, C. y Lee, J. (directores). (2013). Frozen: el reino de hielo [Cinta cinematográfica]. Estados Unidos: Walt Disney Animation Studios y Walt Disney Pictures.

Del Vecho, P. y Lasseter, J. (productores) y Clements, R. y Musker, J. (directores). (2009). Tiana y el sapo [Cinta cinematográfica]. Estados Unidos: Walt Disney Pictures.

Digón, P. (2006). El caduco mundo de Disney: propuesta de análisis crítico en la escuela. Comunicar,26, 163-169.

Disney, R. E. y Ernst, D. W. (productores) y varios directores (directores). (2000). Fantasia 2000 [Cinta cinematográfica]. Estados Unidos: Walt Disney Pictures y Walt Disney Feature Animation.

Disney, W. (productor) y Algar, J., Armstrong, S., Beebe, F., Ferguson, N., Handley J., Hee, T., Jackson, W., Kuske, H. y Roberts, B. (directores). (1940). Fantasía [Cinta cinematográfica]. Estados Unidos: Walt Disney Pictures y RKO Pictures.

Disney, W. (productor) y Algar, J., Armstrong, S. Hand, D., Heid, H., Roberts, B., Stterfield, P. y Wright, N. (directores). (1942). Bambi [Cinta cinematográfica]. Estados Unidos: Walt Disney Productions.

Disney, W. (productor) y Algar, J., Geronimi, C. y Kinney, J. (directores). (1949). La leyenda de Sleepy Hollow y el señor sapo [Cinta cinematográfica]. Estados Unidos: Walt Disney Productions.

Disney, W. (productor) y Cottrell, W., Hand, D., Morey, L., Pearce, P. y Sharpsteen, B. (directores). (1937). Blancanieves y los siete enanitos [Cinta cinematográfica]. Estados Unidos: Walt Disney Pictures.

Disney, W. (productor) y Geronimi, C., Jackson, W. y Luske, H. (directores). (1951). Alicia en el País de las maravillas [Cinta cinematográfica]. Reino Unido y Estados Unidos: Walt Disney Productions.

Disney, W. (productor) y Geronimi, C., Jackson, W. y Luske, H. (directores). (1953). Peter Pan [Cinta cinematográfica]. Estados Unidos: Walt Disney Pictures.

Disney, W. (productor) y Geronimi, C., Jackson, W. y Luske, H. (directores). (1955). La dama y el vagabundo [Cinta cinematográfica]. Estados Unidos: Walt Disney Pictures.

Disney, W. (productor) y Reitherman, W. (director). (1963). Merlín, el encantador [Cinta cinematográfica]. Estados Unidos: Walt Disney Pictures.

Disney, W. (productor) y Reitherman, W. (director). (1967). El libro de la selva [Cinta cinematográfica]. Estados Unidos: Walt Disney Productions.

Disney, W. (productor) y Reitherman, W. (director). (1977). Lo mejor de Winnie the Pooh [Cinta cinematográfica]. Estados Unidos: Walt Disney Pictures.

Disney, W. y Walsh, B. (productores) y Stevenson, R. (director). (1964). Mary Poppins [Cinta cinematográfica]. Estados Unidos: Walt Disney Productions. 
Duncum, P. (2007). Aesthetics, Popular Visual Culture, and Designer Capitalism. International Journal of Art \& Design Education,26 (3), 285-295.

Flynn, B. y Goldman, C. (productores) y Williams S. (director). (2006). Salvaje [Cinta cinematográfica]. Estados Unidos: Walt Disney Pictures y CORE Feature Animation.

Fullmer, R. (productor) y Dindal, M. (director). (2000). El emperador y sus locuras [Cinta cinematográfica]. Estados Unidos: Buena Vista Distribution.

Gavin, K. (productor) y Scribner, G. (director). (1988). Oliver y su pandilla [Cinta cinematográfica]. Canadá: Walt Disney Pictures.

Gómez, I. (2017). Princesas y príncipes en las películas Disney (1937-2019). Análisis de la modulación de la feminidad y la masculinidad. Filanderas. Revista Interdisciplinar de Estudios Feminista, 2, 53-74.

Guitlin, T. (2001). La Tersa Utopía de Disney. Letras Libres, 3(28), 12-16.

Hale, J. (productor) y Berman, T. y Rich, R. (directores). (1985). Taron y el caldero mágico [Cinta cinematográfica]. Estados Unidos: Walt Disney Pictures.

Hahn, D. (productor) y Allers, R. y Minkoff, R. (directores). (1994). El rey león [Cinta cinematográfica]. Estados Unidos: Walt Disney Animation Studios y Walt Disney Pictures.

Hernández, F. (2010). Educación y cultura visual. Barcelona: Ediciones Octaedro.

Hibler, W. y Reitherman, W. (prodcutores) y Reitherman, W. (director). (1970). Los Aristogatos [Cinta cinematográfica]. Estados Unidos: Walt Disney Pictures.

Huerta, R. (1999). Imágenes que nos suenan. Aprender a conocer los sonidos del cine y la televisión. Revista Eufonía,16, 65-72.

Jandrić, P., Jeremy, K., Besley, T., Ryberg, T., Suoranta, J. y Hayes, S. (2019). Ciencia postdigital y educación. Communiars, 2, 11-21.

Marí-Sáez, V. M. (1998). Una lectura de "El Rey León": la educación audiovisual en la era del pensamiento único. Educación y Medios, 7, 45-52.

Miller, R. W. y Reitherman, W. (productores) y Lounsbery, J. y Reitherman, W. (directores). (1978). Los rescatadores [Cinta cinematográfica]. Estados Unidos: Walt Disney Productions.

Miller, R. W., Reitherman, W. y Stevens, A. (productores) y Berman, T. y Rich, R. (directores). (1981). Tod y Toby [Cinta cinematográfica]. Estados Unidos: The Walt Disney Company y Walt Disney Animation Studios.

Pérez, I. (2019). La experiencia estética popular: elementos para la acción descolonial. Communiars, 2, 98-115.

Reguillo, R. (2005). Nosotros y los miedos a la construcción política y cultural de los sentimientos. Argentina: FLACSO. 
Reitherman, W. (productor) y Reitherman, W. (director). (1973). Robin Hood [Cinta cinematográfica]. Estados Unidos: Walt Disney Productions.

Ros, N. (2007). El film Shrek: una posibilidad desde la educación artística para trabajar en la formación docente la lectura de la identidad y los valores. Revista Iberoamericana de Educación, 44(6), 1-12.

Shurer, O. (productor) y Clements, R. y Musker, J. (productor). (2016). Vaiana [Cinta cinematográfica]. Estados Unidos: Walt Disney Pictures y Walt Disney Animation Studios.

Spencer, C. (productor) y Bush, J., Howard, B. y Moore, R. (directores). (2015). Zootrópolis [Cinta cinematográfica]. Estados Unidos: Walt Disney Pictures y Walt Disney Animation Studios.

Spencer, C. (productor) y Moore, R. (director). (2012). ¡Rompe Ralph! [Cinta cinematográfica]. Estados Unidos: Walt Disney Animation Studios. 